\title{
Cyclooxygenase-2 in mucosal DC mediates induction of regulatory T cells in the intestine through suppression of IL-4
}

\author{
F Broere ${ }^{1,7}$, MF du Pré ${ }^{2,7}$, LA van Berkel ${ }^{2}$, J Garssen ${ }^{3,4}$, CB Schmidt-Weber ${ }^{5}$, BN Lambrecht ${ }^{6}$, \\ RW Hendriks ${ }^{6}$, EES Nieuwenhuis ${ }^{2}$, G Kraal $^{1}$ and JN Samsom ${ }^{2}$
}

Oral intake of protein leads to tolerance through the induction of regulatory $\mathrm{T}$ cells (Tr cells) in mesenteric lymph nodes (MLNs). Here we show that the inhibition of cyclooxygenase-2 (COX-2) in vivo suppressed oral tolerance and was associated with enhanced differentiation of interleukin (IL)-4-producing T cells and reduced Foxp3 ${ }^{+}$Tr-cell differentiation in MLN. As a result, the functional suppressive capacity of these differentiated mucosal T cells was lost. IL-4 was causally related to loss of tolerance as treatment of mice with anti-IL-4 antibodies during COX-2 inhibition restored tolerance. Dendritic cells (DCs) in the MLN differentially expressed COX-2 and reductionist experiments revealed that selective inhibition of the enzyme in these cells inhibited Foxp3 ${ }^{+}$Tr-cell differentiation in vitro. Importantly, the inhibition of COX-2 in MLN-DC caused increased GATA-3 expression and enhanced IL-4 release by T cells, which was directly related to impaired Tr-cell differentiation. These data provide crucial insights into the mechanisms driving de novo Tr-cell induction and tolerance in the intestine.

\section{INTRODUCTION}

In the intestine, a tight regulation avoids mounting harmful immune responses to dietary antigens and commensal flora, whereas an efficient inflammatory immune response defends the host against pathogens. One of the crucial steps that underlie the development of mucosal tolerance to harmless antigens and bacterial flora is the induction of adaptive regulatory $\mathrm{T}$ cells (Tr cells). ${ }^{1-9}$ Mucosally induced Tr cells are distinct from thymus-derived naturally occurring Tr cells as they differentiate from naive $\mathrm{T}$ cells in the gut-draining mesenteric lymph nodes (MLNs) and Peyer's Patches (PP). ${ }^{9}$ Once formed, mucosally induced Tr cells specifically suppress inflammatory responses to the antigen that was used for tolerization and can transfer tolerance to naive recipients. ${ }^{7-9}$ Unfortunately, the mechanism that leads to adaptive Tr-cell differentiation in the mucosa-draining $\mathrm{LN}$ is largely unclear.

Unique mucosal mediators have been identified that play an essential role in Tr-cell differentiation. One such mediator is transforming growth factor (TGF)- $\beta$, which is abundantly expressed in the mucosal environment, and can by itself lead to the conversion of $\mathrm{CD} 25^{-}$Foxp $3^{-}$cells into CD $25^{+}$Foxp $3^{+} \mathrm{Tr}$ cells. ${ }^{10}$ An additional important mucosal factor is retinoic acid for which recently a synergism with TGF- $\beta$ in Tr cells differentiation was shown. Intestinal dendritic cells (DC) drive enhanced TGF- $\beta$-dependent Tr-cell differentiation in vitro when compared with splenic DCs, and this exclusive capacity of intestinal DCs relies on their ability to convert vitamin A to retinoic acid. ${ }^{11-14}$ The fact that retinoic acid from intestinal DC is also involved in the imprinting of gut tropism on the differentiating Tr cells, enabling them to home to the intestine, underscores the importance of this factor. ${ }^{14-17}$ It is currently unknown how exactly retinoic acid and TGF- $\beta$ induce mucosal Tr cells.

Another regulatory mediator that is intrinsic to the mucosal environment is cyclooxygenase-2 (COX-2), an enzyme that synthesizes prostaglandins from arachidonic acid. In the intestine, COX-2 is constitutively expressed by stromal cells and myeloid

\footnotetext{
${ }^{1}$ Department of Molecular Cell Biology and Immunology, VU Medical Center, Amsterdam, The Netherlands. ${ }^{2}$ Division Gastroenterology and Nutrition, Department of Pediatrics, Erasmus MC - Sophia Children's Hospital, Rotterdam, The Netherlands. ${ }^{3}$ Department of Biomedical Research, Numico Research BV, Wageningen, The Netherlands. ${ }^{4}$ Utrecht Institute for Pharmaceutical Sciences, University of Utrecht, Utrecht, The Netherlands. ${ }^{5}$ Swiss Institute of Allergy and Asthma Research (SIAF), Davos, Switzerland. ${ }^{6}$ Department of Pulmonary Medicine, Erasmus MC, Rotterdam, The Netherlands. ${ }^{7}$ These authors contributed equally to this work. Correspondence: JN Samsom (j.samsom@erasmusmc.nl) 
cells, which is in contrast to other peripheral sites where it is induced upon inflammation. ${ }^{18}$ Evidence for a regulatory role for COX-2 in intestinal immune responses was provided when treatment of mice with the COX-2 inhibitor NS-398 led to loss of tolerance to dietary antigen. ${ }^{19,20}$ In addition, although mice deficient in COX-2 do not show any spontaneous inflammation in the intestine, they have increased susceptibility to chemically induced colonic enteropathy. This is associated with the inability to produce the arachidonic acid metabolite prostaglandin $\mathrm{E}_{2}$ $\left(\mathrm{PGE}_{2}\right) \cdot{ }^{21}$ Although these findings identify a role for COX-2 in mucosal tolerance it is unclear whether the enzyme regulates particular adaptive T-cell immune responses. Moreover, the specific immunological events leading to inflammation in the absence of functional COX-2 are unidentified. Therefore, in this study, we determined whether COX-2 is directly involved in adaptive Tr-cell differentiation in the intestine. Moreover, as it has been reported that interleukin (IL)-4 can mediate enteropathy ${ }^{22}$ and plays an important role in several models of colitis, ${ }^{23,24}$ we aimed to identify whether IL-4 is involved in the inflammatory immune response that occurs in the absence of functional COX-2.

Here we show that the inhibition of COX-2 during protein feed caused loss of tolerance induction, which was associated with an enhanced T-cell-derived IL-4 production and defective Tr-cell differentiation in the MLN. Crucially, treatment of mice with anti-IL-4 antibodies before COX-2 inhibition and protein feed restored oral tolerance. As, predominantly, DC in the MLN expressed COX-2, the role of the enzyme in mucosal T-cell differentiation was further investigated in vitro. COX-2 expression in MLN-DC stimulated the TGF- $\beta$ - and retinoic acid-dependent conversion of naive T cells into Foxp $3^{+} \operatorname{Tr}$ cells. Reciprocally, the inhibition of COX-2 in MLN-DC increased GATA-3 expression and IL-4 secretion by the differentiating T cells. The differentiation of the IL-4-producing cells in the absence of functional COX-2 was directly related to loss of mucosal tolerance as exogenous IL-4 blocked MLN-DC-driven differentiation of Foxp $3^{+}$ mucosal Tr cells. These data establish that COX-2 in MLN-DC is required to control the GATA-3/IL-4 axis, allowing the differentiation of mucosal $\operatorname{Tr}$ cells and subsequent tolerance.

\section{RESULTS}

\section{The COX-2-dependent arachidonic acid metabolism is essential for oral tolerance induction}

As the role for COX-2 in mucosal tolerance has not been shown for the classical model of oral tolerance induction in normal BALB/c mice, mice were treated with NS-398, a competitive inhibitor of COX-2, with a 1000-fold higher affinity for COX-2 than COX-1. During the first $48 \mathrm{~h}$ after oral ovalbumin (OVA) ingestion, mice were treated with the inhibitor every $8 \mathrm{~h}$ as described earlier by Newberry et al., ${ }^{18}$ whereas control mice received vehicle or saline. To assess the effects of COX-2 inhibition on oral tolerance induction, the mice were subjected to a delayed type hypersensitivity (DTH) response consisting of sensitization with OVA in the tail base and a subsequent challenge with OVA in the ears. Treatment with NS-398 during oral OVA administration reduced oral tolerance induction as evidenced by a pronounced increase in ear thickness compared with saline-treated mice (Figure 1a). NS-398 treatment had no effect on the DTH response in control mice. The treatment did not lead to a change in kinetics of tolerance development as at $48 \mathrm{~h}$ postchallenge, the DTH of NS-398-treated and OVA-fed mice remained elevated $\left(8.4 \pm 0.6 \times 10\right.$ per $\left.\mathrm{mm}^{2}\right)$ when compared with tolerant controls $\left(4.8 \pm 0.5 \times 10\right.$ per $\left.\mathrm{mm}^{2}\right)$ and was comparable with that of NS-398-treated DTH controls $\left(10.5 \pm 1.4 \times 10\right.$ per $\left.\mathrm{mm}^{2}\right)$. Moreover, COX-2 inhibition during the first $48 \mathrm{~h}$ after a single dose of oral OVA ingestion did not result in pathological changes in the small intestine, such as expansion of the numbers of lamina propria lymphocytes, crypt expansion, or villus blunting (data not shown).

\section{coX-2-dependent arachidonic acids inhibit differentiation of IL-4-producing cells}

To elucidate whether COX-2 regulates T-cell differentiation in the MLN and PP during tolerance induction, mice were reconstituted with OVA-specific $T$ cells by transfer of OVA-specific T-cell receptor (TCR) transgenic DO11.10 cells. To ensure that OVA feeding to recipients of TCR transgenic cells induces suppression of DTH response and to confirm that COX-2 inhibited this phenomenon, mice reconstituted with DO11.10 cells were treated with NS-398 during OVA feed and subjected to a DTH response. As seen in Figure 1b, oral ovalbumin treatment of recipients of DO11.10 cells induces the suppression of a subsequent DTH response and NS-398 treatment effectively reduced oral tolerance induction. To study T-cell differentiation in the MLN and PP during tolerance induction, BALB/c mice received naive 5,6-carboxy-succinimidyl-fluoresceine ester (CFSE)-labeled DO11.10 CD4 ${ }^{+} \mathrm{T}$ cells, were fed OVA, and 48 and $72 \mathrm{~h}$ later, division of DO11.10 cells in the MLN and the PP was assessed.

The division profile of OVA-specific T cells in MLN and PP at 48 and $72 \mathrm{~h}$ after OVA feed was comparable in vehicle and NS-398-treated mice (Figure 2a and $\mathbf{b}$ and Supplementary Figure 1a online). Moreover, total numbers of $\mathrm{CD} 4{ }^{+} \mathrm{KJ} 1.26^{+}$ cells in MLN were comparable between vehicle and NS-398treated mice $\left(6.6 \times 10^{5} \pm 2.6 \times 10^{5} \mathrm{KJ} 1.26^{+}\right.$cells in the MLN of NS-398-treated mice, compared with $6.6 \times 10^{5} \pm 2.4 \times 10^{5}$ in vehicle-treated mice), excluding that failure of tolerance induction in NS-398-treated mice was due to abortive T-cell proliferation. Phenotypically, no changes in the expression of CD25, CD45RB, and $\alpha_{4} \beta_{7}$ were detected as a result of COX-2 inhibition (data not shown). As COX-2 and NS-398 have been described to directly affect $\mathrm{T}$-cell apoptosis in vitro, ${ }^{25,26}$ annexin- $\mathrm{V}$ expression was determined. After COX-2 inhibition, no differences in antigenspecific apoptotic cells could be observed (data not shown).

To assess whether COX-2 controls the cytokine profile of differentiating T cells, dividing DO11.10 cells in the MLN were monitored. Treatment with NS-398 significantly altered the cytokine profile of the differentiating T cells in the MLN. NS398 enhanced the IL-4 secretion in T cells isolated from MLN at $48 \mathrm{~h}$ after OVA feed, as reflected by an increase in the percentage of IL-4-producing dividing OVA-specific T cells (Figure 2c). Moreover, even though the percentage of interferon (IFN)$\gamma$-secreting OVA-specific T cells did not change after COX-2 

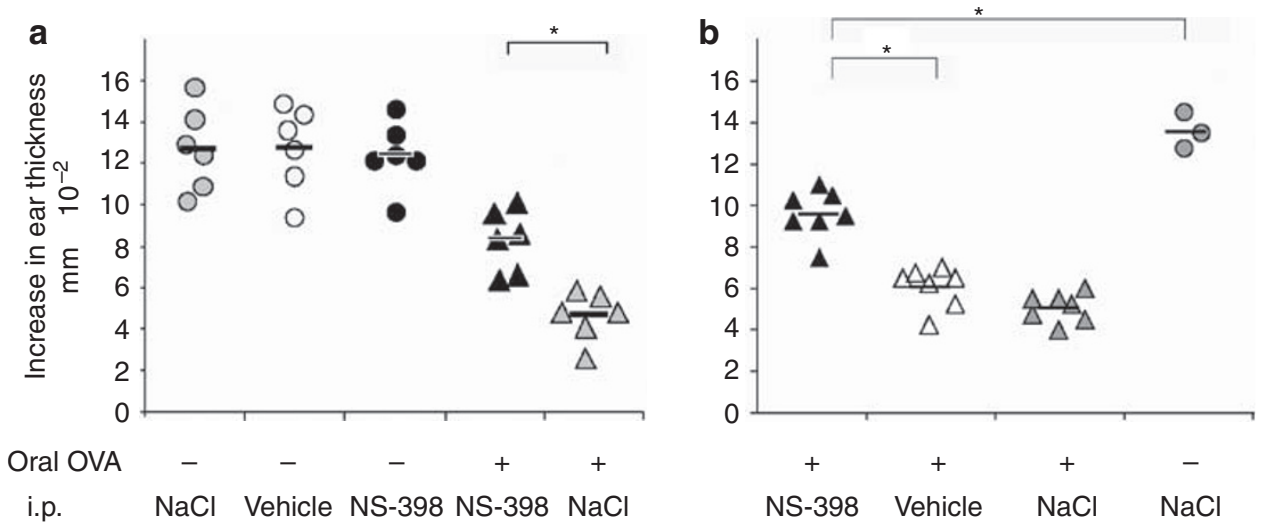

Figure 1 COX-2-dependent PGs are essential during oral tolerance induction. Effect of COX-2 inhibitor (NS-398) on orally induced suppression of a DTH response in BALB/c mice (a). Mice were IP injected six times with $1 \mathrm{mg} \mathrm{kg}^{-1}$ of the selective COX-2 inhibitor, NS-398, saline, or $1 \%$ DMSO at $8 \mathrm{~h}$ intervals. The first IP injection was given $5 \mathrm{~h}$ before tolerance induction via i.g. treatment with $25 \mathrm{mg}$ OVA. Five days after OVA feed, mice were sensitized SC in the tailbase with $100 \mu \mathrm{g}$ OVA in IFA. At day 11, mice were challenged with $10 \mu \mathrm{g}$ OVA in $10 \mu$ l saline in the auricle of both ears, and after $24 \mathrm{~h}$ increases in ear thickness were determined and compared with values before challenge. *Statistically significant $(P<0.05)$. Effect of COX-2 inhibitor (NS-398) on orally induced suppression of a DTH response in D011.10 reconstituted mice (b). BALB/c mice were injected with $1 \times 10^{7}$ CD4 ${ }^{+}$ KJ1-26+ cells i.v., Starting the next day, mice were treated with NS-398 as described above. The first i.p. injection was $5 \mathrm{~h}$ before tolerance induction by a single i.g. dose of $70 \mathrm{mg}$ OVA. Five days after i.g. OVA administration, mice were sensitized SC with OVA in IFA, at day 11 mice were challenged with

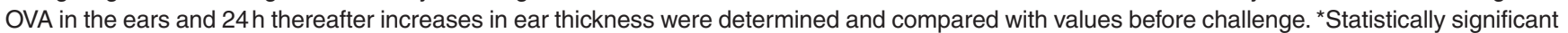
$(P<0.001)$. COX-2, cyclooxygenase-2; DMSO, dimethyl sulfoxide; i.g., intragastric; i.p., intraperitoneal; i.v., intravenous; OVA, ovalbumin; PG, prostaglandin; SC, subcutaneously.

inhibition (Supplementary Figure 1b), the overall release of this cytokine was reduced in MLN cells from NS-398-treated mice (Figure 2d). No differences in IL-5, IL-10, IL-13, or IL-17 were observed (not shown). In agreement, NS-398 treatment of mice during OVA feed induced a twofold increase in GATA3 expression in differentiating OVA-specific $\mathrm{T}$ cells obtained from the gut-draining MLN, whereas T-bet expression was not significantly changed (Figure 2e).

\section{COX-2-dependent arachidonic acid metabolites are required for the development of functional Tr cells during oral tolerance induction}

Conversion of naive $\mathrm{T}$ cells into suppressive $\mathrm{Tr}$ cells in the mucosa-draining $\mathrm{LN}$ is a pivotal event in mucosal tolerance induction. ${ }^{8,9}$ Within $48-72 \mathrm{~h}$ after OVA feed, dividing Foxp3 ${ }^{+}$ $\mathrm{T}$ cells can be detected in MLN (Figure 3a). Although it is unclear whether Foxp3 expression is essential for the functional suppressive capacity of adaptive mucosally induced $\mathrm{Tr}$ cells, it was questioned whether the enhanced IL-4-producing T-cell differentiation during NS-398 treatment was associated with a decreased Foxp $3^{+}$T-cell differentiation. Thereto, dividing $\mathrm{KJ} 1.26^{+} \mathrm{T}$ cells in MLN were analyzed for Foxp3 protein expression and mRNA. At $48 \mathrm{~h}$ after antigen application in NS-398treated mice, a reduced percentage of Foxp $3^{+}$dividing KJ1.26 ${ }^{+}$ $\mathrm{T}$ cells in MLN was observed compared with vehicle control, which correlated with reduced Foxp3 mRNA levels at 24 and $48 \mathrm{~h}$ after OVA feed (Figure $\mathbf{3 b}$ ).

Next, it was assessed whether the gain in IL-4-producing T-cell differentiation and concomitant loss of Foxp $3^{+} \mathrm{Tr}$-cell development resulted in loss of suppressive capacity of the mucosal T cells, explaining the absence of tolerance in COX-2 inhibitor-treated mice. Thereto, the dividing antigen-specific
T cells from MLN of tolerized donors were adoptively transferred to naive recipients as described earlier. ${ }^{8,9}$ At $48 \mathrm{~h}$ after antigen application, $\mathrm{CD} 4^{+}$cells were isolated from MLN and $\mathrm{PP}$ and transferred to naive $\mathrm{BALB} / \mathrm{c}$ recipients that were sensitized and challenged for DTH to read out whether tolerance had developed. Although $\mathrm{CD} 4{ }^{+} \mathrm{T}$ cells from vehicle-treated, tolerized donors could transfer tolerance, this suppressive activity was not seen after transfer of $\mathrm{CD} 4^{+} \mathrm{T}$ cells from MLN and PP of NS-398-treated mice (Figure 3c). This difference in tolerogenic capacity was not due to differences in the frequency of OVA-specific $\mathrm{KJ} 1.26^{+} \mathrm{T}$ cells within the $\mathrm{CD} 4{ }^{+}$fraction between NS-398treated mice $(3.3 \% \pm 1.2)$ and vehicle-treated mice $(3.9 \% \pm 1.5)$. In conclusion, these data indicate that the inhibition of COX-2 impedes the differentiation of functionally suppressive $\mathrm{T}$ cells in the MLN and is associated with enhanced IL-4 production and reduced $\mathrm{Tr}$-cell induction.

\section{Neutralization of IL-4 restores mucosal tolerance in NS-398- treated mice}

To establish whether there is a causative relationship between IL-4 production, loss of Tr-cell differentiation, and loss of functional suppression after NS-398 treatment, in vivo experiments were performed. NS-398-induced IL-4 secretion was neutralized before the inhibition of COX-2 and subsequent development of tolerance to OVA was assessed. Treatment of mice with anti-IL-4 antibodies before NS-398 and OVA administration restored oral tolerance when compared with mice treated with NS-398 and isotype control GL113 or saline (Figure 4). It should be noted that treatment with anti-IL-4 antibodies does not affect the DTH response in unfed controls. ${ }^{27}$ This implicates that enhanced IL4 secretion after COX-2 inhibition causes abrogation of oral tolerance. 
a

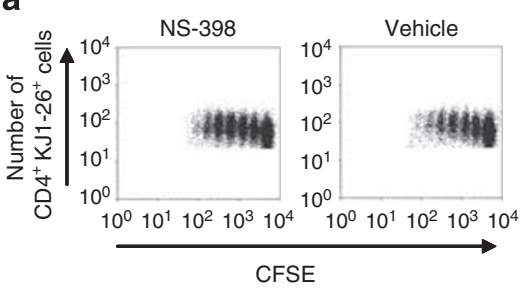

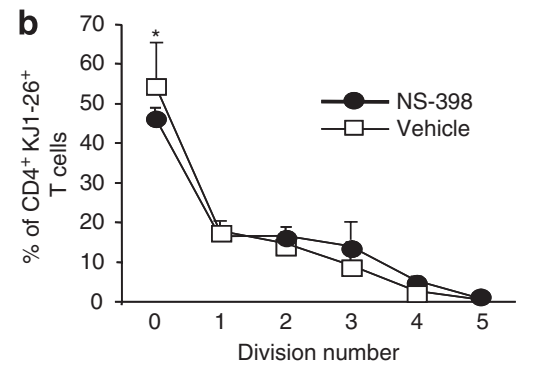

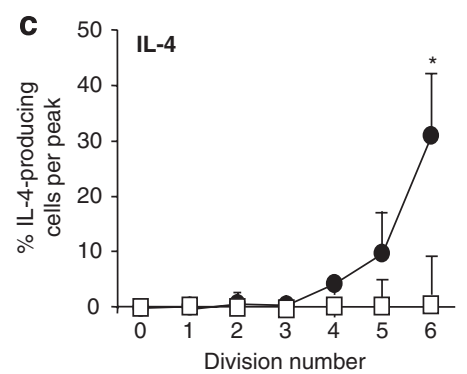

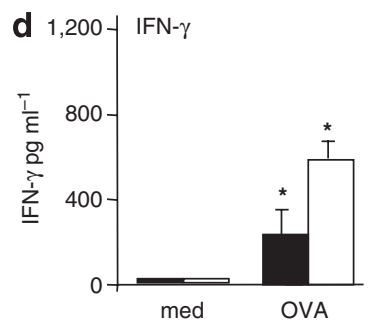

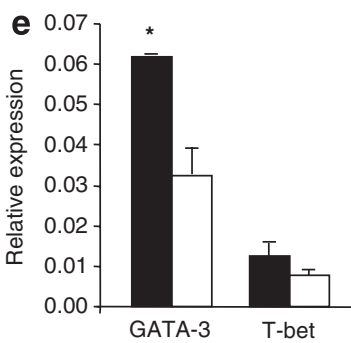

Figure 2 COX-2-dependent arachidonic acids inhibit the differentiation of IL-4-producing T cells in MLN. Donor BALB/c mice were injected with $1 \times 10^{7} \mathrm{CD}^{+} \mathrm{KJ} 1.26^{+}$cells i.v., Starting the next day, mice were treated with NS-398 (black symbols) as described in Figure 1. Control groups were injected with vehicle consisting of a $1 \%$ DMSO solution in saline (white symbols). Tolerization was induced by a single i.g. dose of $70 \mathrm{mg}$ OVA. At $48 \mathrm{~h}$ after OVA administration, MLN and PP (not shown) were isolated and single-cell suspensions were stained for the presence of CD4 ${ }^{+} \mathrm{KJ}^{-2} .26^{+}$cells. CFSE profiles of CD4 ${ }^{+} \mathrm{KJ} 1.26^{+} \mathrm{T}$ cells were determined in MLN by flow cytometry. (a) Representative division plot at $48 \mathrm{~h}$ after OVA feed. (b) The percentages of $\mathrm{CD}^{+}{ }^{+} \mathrm{KJ} 1.26^{+} \mathrm{T}$ cells in each peak of division were calculated and are represented as the mean for at least three mice $\pm \mathrm{s}$.d. (c-e) At $48 \mathrm{~h}$ after oral OVA administration, MLN cells were re-stimulated overnight with $0.5 \mathrm{mg} \mathrm{ml}^{-1}$ OVA or medium at a concentration of $5 \times 10^{6} \mathrm{cells}$ per ml. (c) Single cell suspensions were stained for $\mathrm{KJ} 1.26^{+}$cells and the percentage of IL-4-secreting cells per peak of division was determined with a cytokine secretion assay. Data are represented as mean percentage of OVA-induced cytokine-secreting antigen-specific T cells per peak of division of at least three separate experiments, with s.d. (d) Cytokine concentrations in the supernatants of overnight cultures were determined by cytometric bead array. Data are represented as the mean cytokine concentration of at least three separate mice, with s.d. (e) At 48h after oral OVA administration, dividing OVA-specific T cells were isolated from MLN of three mice and the expression of transcription factors GATA-3 and T-bet was performed by quantitative PCR. *Statistically significant $(P<0.01)$. CFSE, 5,6-carboxy-succinimidyl-fluoresceine ester; COX-2, cyclooxygenase-2; DMSO, dimethyl sulfoxide; i.g., intragastric; IL, interleukin; i.v. intravenous; MLN, mesenteric lymph node; OVA, ovalbumin; PP, Peyer’s Patch.

a

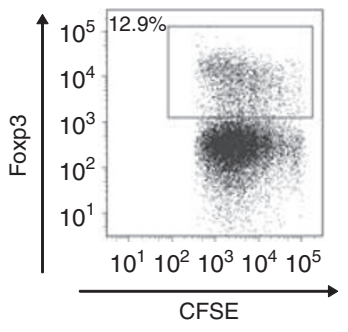

b

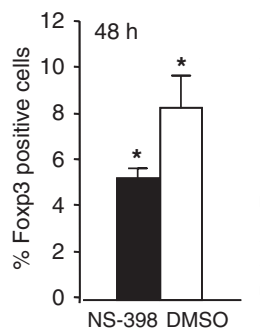

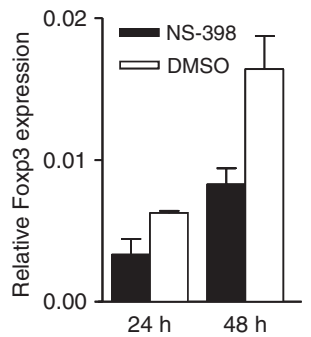

C

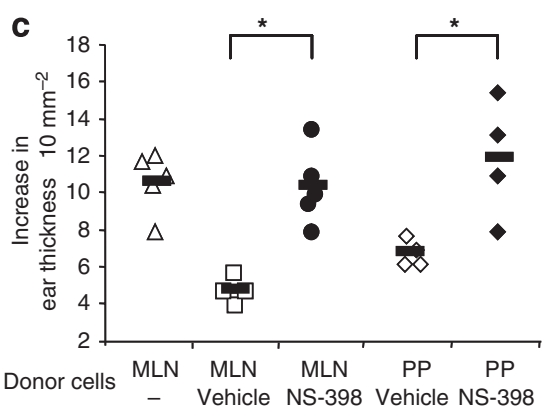

Figure 3 COX-2-dependent PGs are required for functional Tr-cell induction in the gut-draining lymphoid tissue. (a) BALB/c mice enriched with CD4+ $\mathrm{KJ} 1.26^{+} \times \mathrm{RAG}^{-1-} \mathrm{T}$ cells were tolerized as described in Figure 1. Representative dot plot of dividing Foxp3-positive $\mathrm{T}$ cells in the MLN at $72 \mathrm{~h}$ after OVA feed. (b) BALB/c mice enriched with CD4 ${ }^{+} \mathrm{KJ} 1.26^{+}$cells were treated with NS-398 (black symbols) or vehicle (white symbols). At $48 \mathrm{~h}$ after OVA administration, MLNs were isolated and $\mathrm{CD} 4^{+} \mathrm{KJ} 1.26^{+}$cells within single-cell suspensions were analyzed for the percentage of Foxp ${ }^{+}$cells by flow cytometry and Foxp3 mRNA (24 and 48h). (c) At 48 h after feeding, MLN and PP were isolated and single-cell suspensions were enriched for CD4 ${ }^{+}$ cells. A total of $5 \times 10^{5}$ enriched CD4 ${ }^{+}$cells from either NS-398-treated mice (black circles: MLN ; black diamonds: PP cells) or vehicle-treated mice (white squares: MLN cells; PP cells: white diamonds) were transferred to naive BALB/c recipients. As a control, $5 \times 10^{5}$ enriched CD4+ cells isolated from MLN of saline-treated mice as a DTH control (white triangles) were transferred to naive acceptor BALB/c mice. Acceptor mice were sensitized and challenged as described in Figure 1. *Statistically significant $(P<0.05)$. COX-2, cyclooxygenase-2; MLN, mesenteric lymph node; OVA, ovalbumin; PG, prostaglandin; PP, Peyer's Patch; 


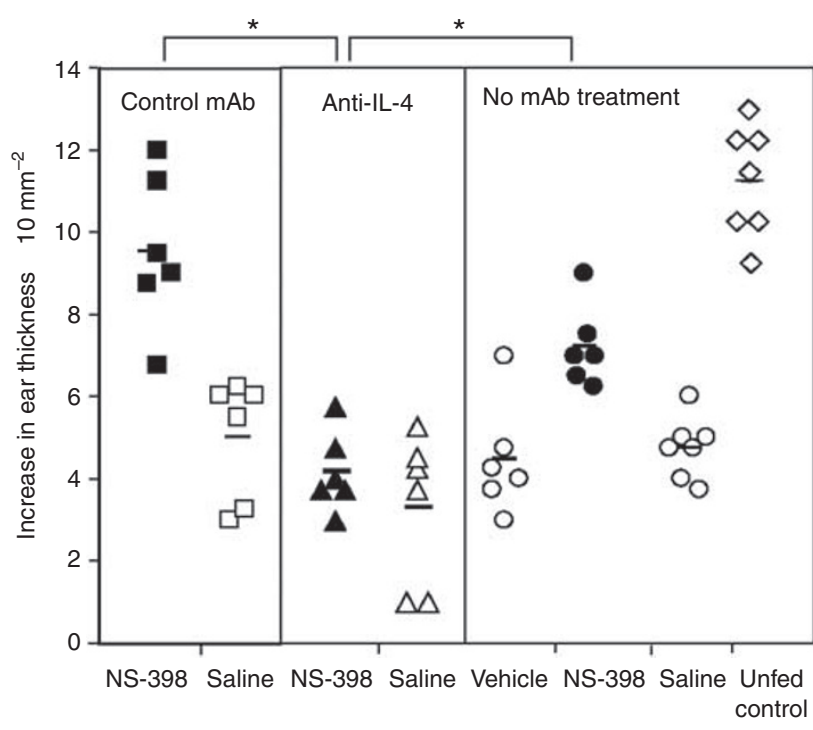

Figure 4 In vivo inhibition of IL-4 secretion during NS-398 treatment. Antibody-treated mice received $1 \mathrm{mg}$ of anti-IL-4 mAb (11B11) or control mAb (GL113) in $200 \mathrm{ml}$ of saline i.p. Starting the next day, mice were injected with NS-398 during OVA treatment, sensitized, and challenged as described in Figure 1. ${ }^{*}$ Statistically significant $(P<0.01)$. $\mathrm{IL}$, interleukin; mAb, monoclonal antibody; i.p. intraperitoneal; OVA, ovalbumin.

\section{COX-2 expression in MLN-DC inhibits GATA-3} and IL-4 differentiation in favor of Tr-cell induction

Further understanding of how COX-2 regulates mucosal T-cell differentiation required the investigation in vitro modeling. Thereto, it was first established whether COX-2 expression occurred in mucosal antigen-presenting cells or whether expression is required in other cell types. At $24 \mathrm{~h}$ after oral treatment of mice with Alexa-Fluor 488-labeled OVA, CD11c ${ }^{+} \mathrm{OVA}-$ $488^{+}$DCs were detected in MLN confirming that MLN-DC had taken up the antigen (Figure 5a). Comparison of quantitative expression of COX-2 in purified CD $11 \mathrm{c}^{+} \mathrm{MHCII}^{+} \mathrm{DC}$ with expression in T cells, B cells, and CD45-negative cells from MLN revealed that the enzyme is primarily expressed in MLN-DC (Figure 5b). Moreover, COX-2 was expressed at relatively higher levels in MLN-DC compared with spleen-DC or peripheral LN-DC (Figure 5b) In particular, CD11b-positive myeloid DC from MLN constitutively expressed COX-2 mRNA, whereas this expression was very low in CD8 $\alpha^{+}$lymphoid and $\mathrm{GR} 1^{+}$plasmacytoid DC (Figure 5c). The expression was not restricted to $\mathrm{CD} 103^{+} \mathrm{MLN}-\mathrm{DC}(\mathrm{COX}-2 \mathrm{mRNA}$ expression relative to cyclophillin in flow sorted cells: $\mathrm{CD} 103^{-} \mathrm{DC}=0.18$ vs. $\left.\mathrm{CD} 103^{+} \mathrm{DC}=0.07\right) \cdot{ }^{11,13}$

To assess whether MLN-DC-derived COX-2 played a role in Tr-cell vs. IL-4-producing T-cell differentiation, an in vitro mucosal Tr-cell differentiation assay was used. MLN-DCs were pretreated with TGF- $\beta$ and retinoic acid, loaded with OVA, and co-cultured with naive DO11.10 $\times \mathrm{RAG}^{-/-} \mathrm{T}$ cells in the presence of retinoic acid and TGF- $\beta$, which induces the differentiation of Foxp $3^{+}$Tr cells in vitro. In agreement with other studies, ${ }^{13}$ stimulation of OVA-loaded MLN-DC with retinoic acid and TGF- $\beta$ dramatically enhanced de novo expression of
Foxp 3 mRNA and protein expression in differentiating OVAspecific T cells (Figure 5d). To establish that COX-2 expression in MLN-DC is involved in the conversion of naive T cells into Tr cells, we assessed whether incubation with NS-398 inhibited Tr-cell differentiation. Indeed, neutralization of COX-2 in the MLN-DC T-cell co-culture consistently inhibited Foxp3 mRNA expression and reduced the frequency of Foxp $3^{+}$cells in the differentiating T cells (Figure 5d). To assess whether the effect of COX-2 inhibition is the same in non-mucosal DCs expressing low levels of COX-2, bone-marrow-derived DCs, which express at least 2- to 10-fold lower levels of mRNA, were used. As seen in Supplementary Figure $2 a-c$, the inhibition of COX-2 in coculture of bone-marrow-derived DC with TGF- $\beta$ and retinoic acid reduced the percentage of differentiating Foxp3-positive cells (a), the degree of Foxp3 expression per cell (b), and the Foxp3 mRNA levels (c). Together, these data show that constitutive COX-2 expression in MLN-DC gives rise to arachidonic acid metabolites that enhance Foxp3 induction in differentiating $\operatorname{Tr}$ cells.

To identify whether reduced Tr-cell differentiation during COX-2 inhibition is associated with concomitant IL-4-producing T-cell differentiation, we monitored the cytokine profile of the T cells that differentiate in the presence and absence of NS-398 in MLN-DC DO11.10 co-culture. Thereto, MLN-DCs were pretreated with TGF- $\beta$ and retinoic acid, loaded with OVA, and co-cultured with DO11.10 cells in the presence of NS-398 or dimethyl sulfoxide. Differentiating T cells were analyzed for cytokine profile and transcription factor expression of the typical polarized effector cell subsets Th1 (IFN- $\gamma$ ), Th2 (IL-4), and Th17 (IL-17). Upon inhibition of COX-2, the differentiating T cells expressed increased amounts of IL-4 (Figure 5e) but did not alter the expression of IFN- $\gamma$ or IL-17 (data not shown). In agreement with the IL-4-producing profile, the differentiating T cells expressed increased amounts of the transcription factor GATA-3 (Figure 5e).

As it has been reported that $\mathrm{PGE}_{2}$ is the most predominant COX-2-dependent arachidonic acid metabolite in the intestine and as $\mathrm{PGE}_{2}$ can induce de novo Foxp3 expression in CD25 T cells, ${ }^{28}$ we hypothesized that MLN-DC-derived PGE $_{2}$ may be one of the COX-2-dependent metabolites that modulates Foxp3 expression and Tr-cell conversion of OVA-specific $\mathrm{T}$ cells by MLN-DC. If so, then $\mathrm{PGE}_{2}$ should be able to mimic COX-2 function in MLN-DC and enhance the differentiation of Foxp3-positive T cells and suppress IL-4-producing T-cell differentiation. TGF- $\beta$-stimulated MLN-DCs were loaded with OVA, incubated with OVA-specific T cells in the presence of $\mathrm{PGE}_{2}$ or retinoic acid, and quantitative mRNA expression in dividing OVA-specific T cells was determined at $96 \mathrm{~h}$ of culture. Although incubation with $\mathrm{PGE}_{2}$ slightly decreased the kinetics of T-cell division it significantly enhanced differentiation of Foxp $3^{+}$Tr cells (Figure 6a and b). Moreover, $\mathrm{PGE}_{2}$ increased the mRNA expression of Foxp3 (Figure 6b), showing that $\mathrm{PGE}_{2}$ can elicit de novo induction of Foxp3.

The finding that COX-2-derived prostaglandins could suppress IL-4-producing T-cell differentiation was corroborated by the observation that culture of OVA-loaded MLN-DC with 


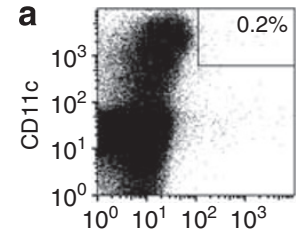

OVA

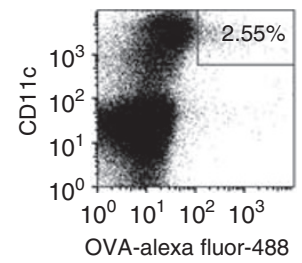

b

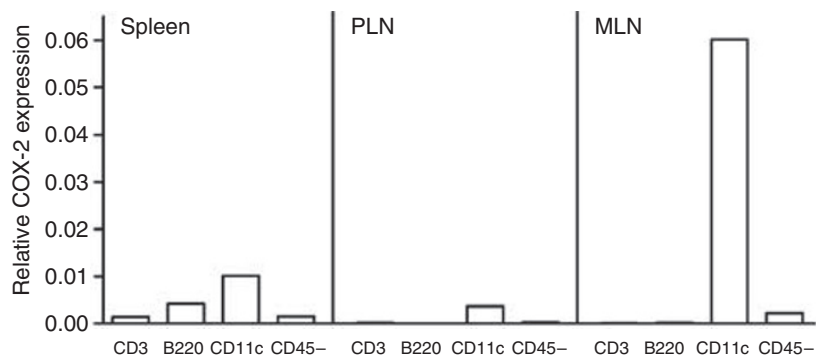

CD3 B220 CD11c CD45- CD3 B220 CD11c CD45- CD3 B220 CD11c CD45-

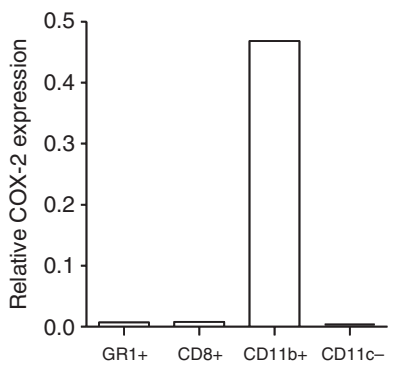

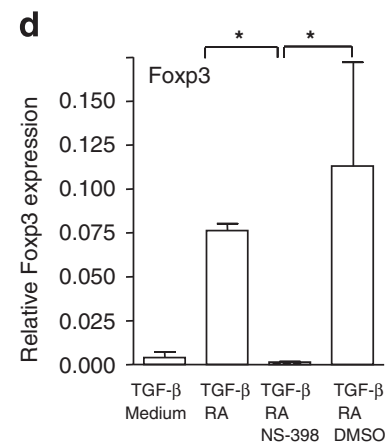
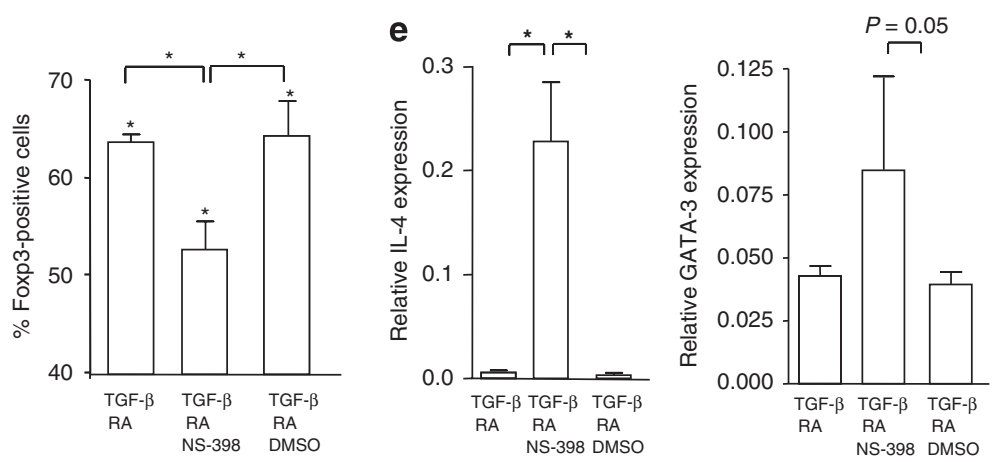

Figure 5 COX-2 expression in MLN-DC regulates mucosal Tr-cell conversion and suppresses IL-4-producing T-cell differentiation. (a) Mice were fed with $5 \mathrm{mg}$ OVA labeled with Alexa Fluor-488 succinimydyl ester in $200 \mu \mathrm{l}$ saline. At $24 \mathrm{~h}$ after antigen administration, MLNs were isolated and single-cell suspensions were stained for CD11c. The percentage of DC that had ingested OVA were determined by gating on the CD11c and Alexa Fluor-488 double-positive population and compared with the overall CD11c-positive population. (b) MLN, spleen, and peripheral LN of naive BALB/c mice were isolated, and DCs, T cells, B cells, and CD45 cells were purified by flow cytometric cell sorting and were compared for COX-2 expression relative to cyclophillin by quantitative PCR. (c) DC subsets were purified from MLN of naive BALB/c mice by flow cytometric cell sorting and were compared for COX-2 expression relative to cyclophillin by quantitative PCR. (d and e) MLN-DCs $\left(2 \times 10^{4}\right)$ were preincubated with $0.2 \mu \mathrm{g} \mathrm{ml} \mathrm{I}^{-1} \mathrm{OVA}$ peptide with or without retinoic acid and with or without TGF- $\beta$ for $6 \mathrm{~h}$. After washing, the cells were incubated with $5 \times 10^{5} \mathrm{CFSE}-\mathrm{labeled} \mathrm{CD} 4^{+} \mathrm{KJ} 1.26^{+} \mathrm{T}$ cells in the presence of TGF- $\beta$ and retinoic acid for $96 \mathrm{~h}$. To assess the role of COX-2, NS-398 $75 \mu \mathrm{M}$ or DMSO control was added to the co-culture. At $96 \mathrm{~h}, \mathrm{CD} 4{ }^{+}$ T cells were isolated from the culture by eliminating DCs with mAbs and anti-rat magnetic beads and analyzed for Foxp3 expression (d), Th2 cytokine profile IL-4 (e), and transcription factor GATA-3 (e) mRNA expression by quantitative PCR. In parallel, CD4 ${ }^{+} \mathrm{KJ} 1.26^{+}$cells were analyzed for Foxp3 by flow cytometry $(\mathbf{d})(n=3)$. *Statistically significant $(P<0.05)$. CFSE, 5,6-carboxy-succinimidyl-fluoresceine ester; COX-2, cyclooxygenase-2; DCs, dendritic cells; DMSO, dimethyl sulfoxide; RA, retinoic acid; TGF- $\beta$, transforming growth factor- $\beta$.

$\mathrm{PGE}_{2}$ and TGF- $\beta$ suppressed IL-4 expression in dividing OVAspecific $\mathrm{T}$ cells at $96 \mathrm{~h}$ of culture as compared with TGF- $\beta$ alone (Figure 6c). This $\mathrm{PGE}_{2}$-mediated IL-4 suppression was independent of MLN-DC activity as PGE 2 also inhibited IL-4 release of polyclonally activated DO.11.10 cells (Figure 6d).

In conclusion, MLN-DC-derived COX-2-dependent arachidonic acid metabolites suppress GATA-3 expression and IL-4 release in favour of mucosal Tr-cell differentiation.

\section{NS-398-induced GATA-3 and IL-4 abrogate adaptive Tr-cell induction in vitro}

To establish whether there is a direct mechanistic link between IL-4 production and loss of mucosal Tr-cell differentiation during NS-398 treatment, we assessed whether exogenous IL4 could block MLN-DC-induced Tr-cell differentiation in the presence of TGF- $\beta$ and retinoic acid in vitro. Thereto, MLNDCs were loaded with OVA and co-cultured with DO11.10 cells in the presence of TGF- $\beta$, retinoic acid, and recombinant IL-4. When exogenous recombinant IL- 4 was added to the culture, differentiation of Foxp $3^{+}$Tr cells was dramatically inhibited (Figure 7a and $\mathbf{b}$ ). Reciprocally, the addition of neutralizing anti-IL-4 antibodies during COX-2 inhibition with NS-398 partially restored the differentiation of Foxp3-positive Tr cells (Figure 7c).

Likewise, transgenic overexpression of GATA-3 in the DO11.10 cells during T-cell differentiation blocked the conversion of naive $\mathrm{T}$ cells into $\mathrm{Tr}$ cells (Supplementary Figure 2d online). The latter effect was only partially mediated by GATA-3-driven IL-4 secretion as neutralization of IL-4 partially restored the differentiation of Foxp3-positive cells (Supplementary Figure $2 \mathbf{e}$ online). Measurement of the concentration of IL-2 in the supernatant of the in vitro Tr-cell differentiation assay revealed that the addition of exogenous IL-4 dramatically reduced the concentration of IL-2 in the cultures (Supplementary Figure $2 \mathrm{f}$ online). This effect was also seen in the cultures with GATA$3 \times \mathrm{DO} 11.10 \mathrm{Tg} \mathrm{T}$ cells (Supplementary Figure $2 \mathrm{f}$ online). As it has become clear that the presence of the cytokine IL-2 is crucial for the conversion of TGF- $\beta$-induced Tr cells, this could be one 

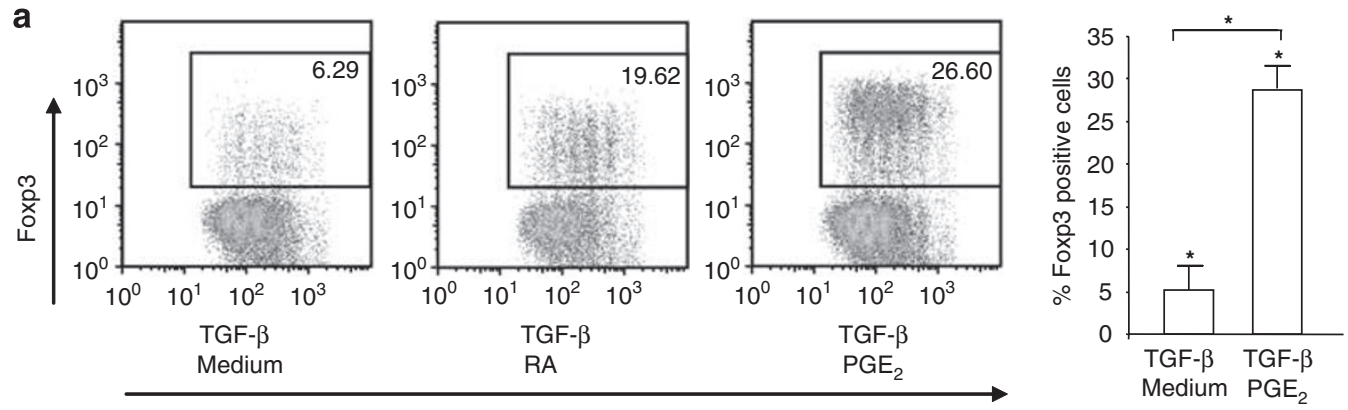

CFSE
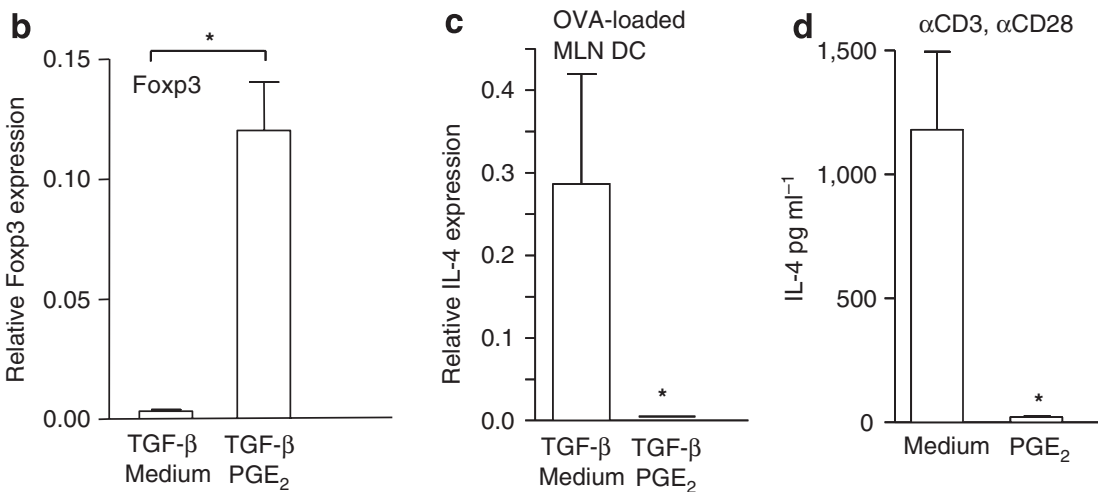

Figure $6 \mathrm{PGE}_{2}$ enhances Tr differentiation and concomitantly inhibits Th2 differentiation. (a and $\left.\mathbf{b}\right) \mathrm{MLN}-\mathrm{DCs}\left(2 \times 10^{4}\right)$ preincubated with $0.2 \mu \mathrm{g} \mathrm{ml}^{-1}$ OVA peptide with or without retinoic acid and/or TGF- $\beta$ for $6 \mathrm{~h}$. After washing, the cells were incubated with $5 \times 10^{5} \mathrm{CFSE}-\mathrm{labeled}$ CD4 ${ }^{+} \mathrm{KJ} 1.26^{+} \mathrm{T}$ cells in the presence of TGF- $\beta$ with or without retinoic acid for $96 \mathrm{~h}$. For analysis of $\mathrm{PGE}_{2}$ effects, $\mathrm{CD} 4^{+} \mathrm{KJ} 1.26^{+}$T cells were stimulated with 16,16 -dimethyl prostaglandin $\mathrm{E}_{2}(26 \mu \mathrm{m}) 2 \mathrm{~h}$ before the start of the culture as well as during the $96 \mathrm{~h}$ culture. At $96 \mathrm{~h}, \mathrm{CD} 4^{+} \mathrm{KJ} 1.26^{+}$cells were analyzed for Foxp3 by flow cytometry $(n=3)$. (b and c) CD4 ${ }^{+}$T cells were isolated from the culture by eliminating DC with mAbs and anti-rat magnetic beads and analyzed for Foxp3 - (b) and IL-4 - (c) mRNA expression by PCR. (d) A total of $5 \times 10^{5}$ CFSE-labeled CD4 ${ }^{+} \mathrm{KJ} 1.26^{+} \mathrm{T}$ cells were stimulated with anti-CD3 $\left(10 \mu \mathrm{g} \mathrm{ml}^{-1}\right)$ and anti-CD28 $\left(10 \mu \mathrm{g} \mathrm{ml}^{-1}\right)$ in the absence of TGF- $\beta$ and presence of 16,16-dimethyl prostaglandin E2 $(26 \mu \mathrm{M})$ for $72 \mathrm{~h}$. Release of IL-4 in cell culture supernatants was determined by cytometric bead array (CBA). *Statistically significant $(P<0.05)$. CFSE, 5,6-carboxy-succinimidylfluoresceine ester; DCs, dendritic cells; IL, interleukin; $\mathrm{mAb}$, monoclonal antibody; $\mathrm{MLN}$, mesenteric lymph node; $\mathrm{PGE}_{2}$, prostaglandin $\mathrm{E}_{2}$; RA, retinoic acid; TGF- $\beta$, transforming growth factor- $\beta$.

of the mechanisms by which IL-4 inhibits Tr-cell induction. ${ }^{10}$ These data establish that the activation of the GATA-3/IL-4 axis in differentiating $\mathrm{T}$ cells blocks the conversion to the TGF$\beta$-elicited Foxp $3^{+}$Tr-cell phenotype.

\section{DISCUSSION}

In this study, we show that COX-2 expression in MLN-DC is involved in the induction of Tr cells during oral tolerance. COX- 2 acts by downregulating GATA- 3 and IL- 4 release in differentiating T cells. IL-4 was found to be a crucial factor that inhibits oral tolerance and impedes the conversion of naive $\mathrm{T}$ cells into mucosal Tr cells during COX-2 inhibition. Our data shed new light on the earlier findings showing a role of COX-2 in mucosal homeostasis, ${ }^{19-21}$ as they show that COX-2-dependent arachidonic acid metabolites determine the phenotype of the adaptive intestinal immune responses and regulate de novo Tr-cell induction in the mucosal immune system by the suppression of IL-4-producing T cells.

It has been shown that orally induced antigen-specific $\operatorname{Tr}$ cells can develop in the absence of naturally occurring $\operatorname{Tr}$ cells. ${ }^{29}$ Conversion of naive $\mathrm{T}$ cells into functional mucosal $\mathrm{Tr}$ cells occurs in the mucosa-draining lymphoid tissue within $48-72 \mathrm{~h}$ after antigen encounter. ${ }^{8,9}$ In agreement, it was recently estab- lished that MLN-DCs and lamina propria DCs induce increased TGF- $\beta$-dependent Foxp $3^{+}$Tr-cell differentiation when compared with splenic DCs. ${ }^{12,13}$ One of the factors that control peripheral Tr-cell differentiation at this immune-privileged site is the vitamin A derivative retinoic acid. ${ }^{13}$ The current data show that COX-2 expression in MLN-DC contributes to this $\mathrm{Tr}$-cell differentiation. Constitutive expression of COX-2 exclusively occurs in the intestine. Transient inhibition of this single enzyme during soluble protein feed suppressed $\mathrm{Tr}$-cell differentiation in PP and MLN within $48 \mathrm{~h}$. As COX-2 can be expressed by stromal cells in the lamina propria ${ }^{18}$ as well as by DC in the MLN, its contribution to Tr-cell differentiation could be direct, by influencing DC-T-cell contact within the MLN, or indirect by "imprinting" lamina propria DCs that migrate to the MLN. This study reveals that MLN-DC-derived COX2 is directly involved in the commitment of Foxp $3^{+} \mathrm{Tr}$ cells as inhibition of the enzyme in an MLN-DC-T-cell co-culture significantly inhibited the differentiation of TGF- $\beta$-induced $\mathrm{Tr}$ cells. One of the functions of COX-2 products is to negatively regulate GATA-3 expression and IL-4 synthesis. We and others have shown earlier that Th2 differentiation is competing with Tr-cell commitment. ${ }^{30-33}$ These novel data show that retinoic acid- and TGF- $\beta$-induced mucosal Tr differentiation is also 

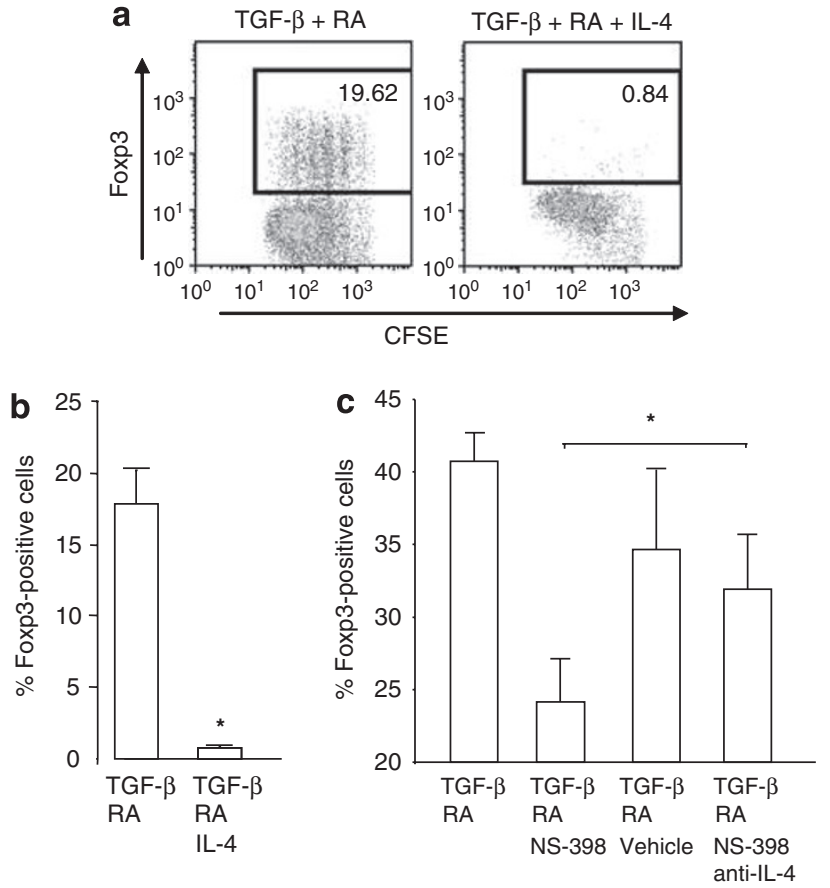

Figure 7 IL-4 inhibits TGF- $\beta$-induced adaptive Tr-cell conversion. MLN-DCs were loaded with $0.2 \mu \mathrm{g} \mathrm{ml}^{-1}$ OVA peptide during $6 \mathrm{~h}$. After washing, $2.0 \times 10^{4} \mathrm{MLN}-\mathrm{DC}$ were incubated with $5 \times 10^{5} \mathrm{CFSE}$-labeled CD4 ${ }^{+} \mathrm{KJ} 1.26^{+} \mathrm{T}$ cells in the presence of TGF- $\beta$ and retinoic acid during $96 \mathrm{~h}$ and analyzed for Foxp3 expression and CFSE content by flow cytometry. (a) Representative flow cytometric analysis of Foxp3 expression in the presence or absence of exogenous recombinant IL-4 (b) combined data $n=3$. (c) To determine whether the IL-4 that is produced during COX-2 inhibition directly interferes with Foxp3 expression, cells were cultured with NS-398 and anti-IL-4 $\left(10 \mu \mathrm{g} \mathrm{ml}^{-1}\right.$; purified from 11B11 hybridoma). At $96 \mathrm{~h}$, the cells were analyzed for Foxp3 expression. CFSE, 5,6-carboxy-succinimidyl-fluoresceine ester; COX-2, cyclooxygenase-2; DCs, dendritic cells; IL, interleukin; MLN, mesenteric lymph node; OVA, ovalbumin; RA, retinoic acid; TGF- $\beta$, transforming growth factor- $\beta$.

${ }^{*} \mathrm{P}<0.05$

inhibited by IL-4. In part, this may be mediated by the direct suppression of the FOXP3 promoter by GATA-3. ${ }^{30}$ The current in vivo experiments show that COX-2 inhibition drives GATA- $3^{+-}$and IL-4-producing T cells in the MLN, which have lost their regulatory capacity. Neutralization of IL-4 production restored tolerance suggesting that IL- 4 is a pivotal factor responsible for loss of tolerance in vivo. Thus, it can be hypothesized that there are two processes that may impede the differentiation of functionally suppressive T cells in the MLN during COX-2 inhibition. First, COX-2 inhibition reduces the differentiation of Foxp3-positive cells. However, as this is not a full ablation the total prevention of transfer of tolerance by the MLN cells may additionally be caused by the reciprocal formation of inflammatory, IL-4-secreting, effector T cells. Whether COX-2 activity in stromal cells contributes to the adaptive T-cell response through "imprinting" of lamina propria DC remains to be established. Moreover, it is not expected that T-cell-derived COX-2 plays an important role as COX-2 expression was not observed in any of our experiments irrespective of whether $\mathrm{T}$ cells were differentiated in vivo or in vitro. Very recent data confirm that drug-medi- ated COX-2 inhibition is also effective to decrease T-Bet and IFN- $\gamma$ in a model of autoimmune encephalomyelitis, suggesting that COX-2 may regulate Th-cell differentiation depending on the inflammatory environment. ${ }^{34}$

The finding that IL-4 inhibits Tr-cell differentiation and causes loss of mucosal tolerance is supported by studies showing the detrimental role of IL-4 in intestinal homeostasis. In particular, it was shown that parasite-induced IL-4 can drive enteropathy, IL-4 causes crypt hyperplasia and recruitment of intraepithelial lymphocytes in murine jejunal graft vs. host reaction, and IL-4 plays an important role in the development of colitis in TCR $\alpha^{-1-}$ mice. ${ }^{22,23,35}$ Moreover, earlier reports have shown that IL-4-deficient mice are not hampered in tolerance induction. ${ }^{36}$ At the first instant, the inhibitory effect of IL-4 on mucosal Tr-cell induction seems difficult to reconcile with the fact that mucosally induced Th 3 cells generated by myelin basic protein feed are characterized by IL- 4 production and can be expanded in vitro with this particular cytokine. ${ }^{1}$ However, the stage of differentiation at which the IL-4 is produced may crucially determine how it affects Tr-cell numbers. IL-4 potently inhibits IL-2 production. ${ }^{37}$ This is also seen in our in vitro $\mathrm{Tr}$-cell differentiation experiments in which a strong reduction of IL-2 release was observed when OVA-specific $\mathrm{T}$ cells were cultured with IL-4 or when GATA-3 tg OVA-specific T cells were used. This IL-2 reduction will most likely have an effect on the initial stages of $\mathrm{Tr}$ conversion as it was shown that IL-2 is essential for TGF- $\beta$ to convert naive CD $4^{+} \mathrm{CD} 25^{-}$T cells to CD $25^{+}$Foxp $3^{+}$ $\operatorname{Tr}^{38}$ However, other common $\gamma$-chain cytokines, such as IL-4, IL-7, and IL-15, can sustain maintenance of committed Foxp3 ${ }^{+}$ Tr cells. ${ }^{38}$ Thus, it can be envisaged that IL-4 inhibits Tr cells at the stage of acquisition of the Tr-cell phenotype through the inhibition of IL-2 without affecting earlier differentiated Foxp $3^{+}$ $\operatorname{Tr}$ cells. Besides facilitating Tr-cell differentiation through negatively regulating the GATA-3/IL-4 pathway, COX-2-dependent metabolites may also positively induce Foxp3 expression. Earlier, it has been reported that the COX-2-dependent metabolite $\mathrm{PGE}_{2}$ is able to induce Foxp3 gene expression in murine and human $\mathrm{CD} 4^{+} \mathrm{CD} 25^{-} \mathrm{T}$ cells. ${ }^{28,39}$ Although the molecular mechanism of this positive gene regulation is unclear we were able to show that $\mathrm{PGE}_{2}$ can dramatically enhance Foxp3 expression during OVAspecific Tr-cell conversion induced by MLN-DC. Whether $\mathrm{PGE}_{2}$ is the only main COX-2-dependent metabolite that controls Trcell conversion in MLN in vivo remains to be established. Similar properties may be shared by other prostaglandins metabolites as the activation of the $\mathrm{D}$ prostanoid 1 receptor in a murine model for asthma was also associated with protection and induction of Tr cells and $\mathrm{PGI}_{2}$ has been shown to downregulate DC functions. ${ }^{40,41}$ However, $\mathrm{PGE}_{2}$ clearly plays a crucial role in both small intestinal as well as colonic homeostasis. Quantitatively, in lamina propria stromal cells, $\mathrm{PGE}_{2}$ is the most predominant COX-2-dependent arachidonic acid metabolite present, whereas COX-2-dependent production of $\mathrm{PGF}_{2} \alpha, 6$-keto $\mathrm{PGF}_{1} \alpha, \mathrm{TXB}_{2}$, and $\mathrm{PGD}_{2}$ is much lower. ${ }^{18,19}$ Functionally, $\mathrm{PGE}_{2}$ also seems have dominant regulatory functions as deficiency in EP4, one of the G-coupled $\mathrm{PGE}_{2}$ receptors, causes increased susceptibility to chemically induced colitis, whereas deficiency in the PGD 
receptor (DP), the PGF receptor (FP), the PGI receptor (IP), or the TX receptor (TP) did not have this effect. ${ }^{42}$ Intriguingly, deficiency in the other three subtypes of PGE receptor (EP1, EP2, and EP3) did not have the same effect. ${ }^{42}$

The expression of COX-2 in DC in the gut-draining lymphoid tissue is very unique for this microenvironment. Little is known about the factors that regulate the expression of the enzyme. Recently, it has been shown that in the colon, COX-2 expression is dependent on TLR4 triggering by bacterial components. ${ }^{43}$ However, as TLR-4-independent COX-2 expression has been observed in lamina propria stromal cells, ${ }^{18}$ it is possible that local non-inflammatory mediators may also mediate COX-2 expression..$^{44,45}$ Although CD103+ ${ }^{+}$MLN-DCs were reported to selectively induce Foxp3- and CCR9- expression in differentiating $\mathrm{T}$ cells when compared with $\mathrm{CD} 103^{-} \mathrm{DCs},{ }^{11,16,17} \mathrm{COX}-2$ expression was measured in both subsets but in contrast was particularly distinctive in $\mathrm{CD} 11 \mathrm{~b}^{+} \mathrm{DCs}$.

Our data, generated in mouse models, show a crucial role for COX-2-dependent arachidonic acid metabolites in the induction of adaptive regulatory $\mathrm{T}$ cells and maintenance of mucosal tolerance in the intestine. Whether this exact mechanism of regulation also applies to the human situation will require extensive further research. Clearly, many reports support the notion that prostaglandin-mediated regulation also occurs in the human intestine. In the past decades, the administration of inhibitors of COX enzymes, denoted as non-steroidal anti-inflammatory drugs, to patients with chronic inflammatory intestinal disease has become more controversial due to the effects of exacerbation of the disease. ${ }^{46-49}$ Moreover, recently, a major new Crohn's disease susceptibility locus was identified close to the gene PTGER4 encoding $\mathrm{EP} 4,{ }^{50}$ further supporting the idea that modulating inflammation through long-term intake of COX-2 inhibitors may interfere with crucial immune regulatory processes and may therefore encompass threats to intestinal homeostasis.

In conclusion, besides unravelling the molecular mechanism of de novo $\mathrm{Tr}$-cell induction in the peripheral mucosal immune system, the finding that COX-2-mediated prostaglandins regulate adaptive T-cell responses through the inhibition of IL-4 will stimulate further research into the function of this enzyme in inhibiting chronic intestinal inflammatory disease.

\section{METHODS}

Mice. Specific pathogen-free BALB/c mice (8-10 weeks) were purchased from Charles River (Maastricht, The Netherlands). DO11.10 transgenic (Tg) mice and DO11.10tg $\times \mathrm{RAG}^{-1-}$ mice, which have a Tg TCR specific for the OVA 323-339 peptide, were bred at our own facility. CD2-GATA$3 \mathrm{Tg}$ and DO11.10×CD2-GATA-3 mice were generated as described earlier. ${ }^{51}$ All mice were kept under routine animal housing conditions and experiments were approved by the animal experimental committee of the VUMC or the Erasmus MC.

Antibodies and antigen. In all in vivo experiments, intact $98 \%$ pure OVA (either from Sigma Aldrich (Zwijndrecht, The Netherlands) or from Calbiochem (San Diego, CA)) was used. In in vitro experiments, either intact OVA (Calbiochem) or OVA $323-339$ peptide was used. The anticlonotypic $\mathrm{mAb}$ for the DO11.10 Tg TCR (KJ1.26) was purified from culture supernatant and biotinylated, according to the manufacturer's protocol (Molecular Probes, Leiden, The Netherlands). Anti-CD11c
(HL3), anti-CD4 (GK1.5), anti-CD3 (145-2C11), anti-CD25 (PC61), anti-CD45RB (16A), anti-B220 (RA3-6B2), anti- $\alpha 4 \beta 7$ (DATK32), anti-MHC-II (M5/114), anti-CD8 $\alpha$ (53-6.7), anti-Gr1 (RB6-8C5), and appropriate isotype control antibodies were purchased from BD Pharmingen (Woerden, The Netherlands). Conjugates that were used for flow cytometry were, streptavidin-CyChrome, streptavidin-PerCP, streptavidin-APC (BD Pharmingen), and anti-rat-PE (Jackson laboratories, West Baltimore, MD).

Adoptive transfer and CFSE labeling. Lymph nodes and spleens were isolated from DO11.10 mice and single-cell suspensions were prepared, enriched for $\mathrm{CD}^{+}{ }^{+} \mathrm{T}$ cells as described earlier, ${ }^{8,9}$ and labeled with CFSE (Molecular Probes) to be able to follow their division profiles in vivo. Each mouse received $1.10^{7} \mathrm{CD}^{+} \mathrm{KJ}^{+} .26^{+}$cells in $100 \mu \mathrm{l}$ saline by intravenous injection.

Delayed-type hypersensitivity response. Mice were injected intraperitoneally six times at 8 -h intervals with $1 \mathrm{mg} \mathrm{kg}^{-1}$ of the freshly dissolved selective COX-2 inhibitor NS-398 (Alexis, Breda, The Netherlands) in saline as described by Newberry et al. ${ }^{19}$ Control groups were injected with saline alone or vehicle consisting of a $1 \%$ dimethyl sulfoxide solution in saline. The first injection of NS-398 was given $5 \mathrm{~h}$ before intragastric (i.g.) administration of $25 \mathrm{mg}$ OVA in $200 \mu \mathrm{l}$ saline (Sigma Aldrich). Five days after i.g. OVA administration, mice were sensitized subcutaneously in the tail base with $100 \mu \mathrm{g}$ of OVA in $50 \mu \mathrm{l}$ of a 1:1 IFA:saline solution (Difco, BD. Alphen a/d Rijn, The Netherlands). At day 11, mice were challenged with $10 \mu \mathrm{g}$ OVA in $10 \mu \mathrm{l}$ saline in both ears, after $24-\mathrm{h}$ increases in ear thickness were determined and compared with values before challenge. $^{7-9}$

Transfer to assess regulatory function of T cells. Mice were adoptively transferred with DO11.10 cells and treated with NS-398 or vehicle prior and after tolerization with $70 \mathrm{mg}$ OVA 1 day later. ${ }^{9}$ MLN and PP were isolated $48 \mathrm{~h}$ after OVA administration, $\mathrm{CD} 4{ }^{+}$cells were enriched, and $5 \times 10^{5}$ cells were transferred to naive BALB/c mice. Enriched CD ${ }^{+} \mathrm{T}$ cells were routinely pure between 80 and $90 \%$. One day after transfer, the mice were sensitized followed by a DTH challenge in the ears 5 days later.

TGF- $\beta$-induced in vitro Tr-cell differentiation. Bone-marrow-derived DCs were generated as described earlier. ${ }^{52}$ To obtain DC from MLN, tissue was digested with Liberase Blenzyme 3 (Roche, Woerden, The Netherlands) in the presence of DNAse I (Roche) for 30-35 min in a $37^{\circ} \mathrm{C}$ incubator. CD11 $c^{+}$cells were isolated using anti-CD11c MACS beads (Miltenyi Biotec, Bergisch Gladbach, Germany). Purity of the isolated CD11 $\mathrm{c}^{+}$cell subset was $60-80 \%$. DCs were loaded with either $0.5 \mathrm{mg} \mathrm{ml}^{-1}$ OVA (Calbiochem) for $6 \mathrm{~h}$ or with OVA peptide for $2 \mathrm{~h}$. After washing, $2 \times 10^{4}$ bone-marrow-derived DCs or MLN-DCs were

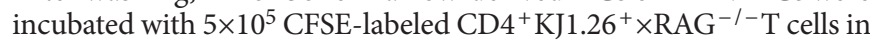
the presence of $20 \mathrm{ng} \mathrm{ml}^{-1}$ rhTGF- $\beta$ (Preprotech, Rocky Hill, NJ) for $96 \mathrm{~h}$ to induce Foxp $3^{+}$T-cell differentiation. Exogenous recombinant IL-4 (300 ng ml ${ }^{-1}$; R\&D systems, Abingdon, UK), anti-IL-4 $\left(10 \mu \mathrm{g} \mathrm{ml}^{-1}\right.$; purified from 11B11 hybridoma), isotype control $\left(10 \mu \mathrm{g} \mathrm{ml}^{-1}\right.$; purified from GL113 hybridoma), NS-398 (75 $\mu \mathrm{M})$, dimethyl sulfoxide (0.09\%) or DO11.10xCD2-GATA-3 cells were used in the culture. In some experiments, DCs were stimulated with $10 \mathrm{nM}$ retinoic acid (Sigma) during OVA loading and as well as during the $96 \mathrm{~h}$ culture. To study the role of $\mathrm{PGE}_{2}$ in Tr conversion, $\mathrm{CD}^{+} \mathrm{KJ}^{+} .26^{+} \times \mathrm{RAG}^{-1-} \mathrm{T}$ cells were stimulated with 16,16-dimethyl prostaglandin $\mathrm{E}_{2}(26 \mu \mathrm{M})$ (Cayman Chemical, Ann Arbor, MI) $2 \mathrm{~h}$ before the start of the culture as well as during the $96 \mathrm{~h}$ culture. After culture, the cells were analyzed for Foxp3 expression (Clone FJK-16S; e-Bioscience, San Diego, CA), intracellular cytokine production, and CFSE content by flow cytometry. In some experiments, CD $4^{+}$ $\mathrm{T}$ cells were isolated from the culture by eliminating $\mathrm{DC}$ with a mix of rat antibodies to B220 (clone 6B2), F4/80, CD11b (MAC-1), MAC-2, MHCII (M5/114), CD8 (53.6.72), and anti-rat magnetic beads (Dynal, Oslo, Norway). 
Flow cytometry. At 48 and $72 \mathrm{~h}$ after i.g. OVA administration, MLN, $\mathrm{PP}$, and spleen were isolated and single-cell suspensions were stained for $\mathrm{CD} 4, \mathrm{CD} 25, \mathrm{CD} 45 \mathrm{RB}$, or $\alpha_{4} \beta_{7}$ and KJ1.26 to determine phenotype and cell division by flow cytometry (FACS Calibur; BD Biosciences, Franklin Lakes, NJ). Cell division was determined based on fluorescence intensity of single CFSE peaks. For further analysis, at least 20,000 KJ1.26 ${ }^{+}$ cells were counted. For the analysis of OVA-containing DCs, mice were fed with $5 \mathrm{mg}$ per mouse of OVA-Alexa-488. At $48 \mathrm{~h}$ after OVA-Alexa488 feed, MLNs were isolated and single-cell suspensions were stained for CD4, CD19, CD40, CD86, CD8 $\alpha$, CD11b, MHC-II, and CD11c.

For obtaining purified populations of T cells, B cells, CD45- cells, DCs, and DC subsets, cells were isolated from $\mathrm{LN}$ as described above. Purified T cells, B cells, DCs, and CD45- cells were obtained in a single step by flow cytometric cell sorting on expression of CD3, B220, CD11c, MHCII, and CD45. DC subsets were purified by negative enrichment of LN cells for DC using a mouse DC enrichment kit (Dynal) and subsequent flow-cytometric cell sorting on expression of CD11b, CD45, CD8 $\alpha$, and Gr-1.

Cytokine secretion. The percentage of cytokine-secreting cells, and the amount of cytokine secreted during a 16-h re-stimulation period, was assessed by isolating MLN and PP at 24, 48, and $72 \mathrm{~h}$ after i.g. OVA administration. Cells were incubated at $5 \times 10^{6}$ cells per $\mathrm{ml}$ with either $0.5 \mathrm{mg} \mathrm{ml}^{-1} \mathrm{OVA}, 100 \mathrm{ng} \mathrm{ml}^{-1}$ OVA peptide, or medium as a control. Cytokine concentrations in supernatants were determined by BD cytometric bead array according to then manufacturer's instructions (BD Pharmingen). Antigen-specific cytokine-secreting cells were determined using the cytokine-specific capture assays for IL- 4 and IFN- $\gamma$ according to the instructions of the manufacturer (Miltenyi Biotech).

Real-time PCR. Total RNA was purified from DC or DO11.10 ${ }^{+} \mathrm{KJ} 1.26^{+}$ $\mathrm{T}$ cells from MLN using the Qiagen RNeasy kit (Westburg, Leusden, The Netherlands). One microgram of RNA was reverse transcribed to single-stranded cDNA using a mix of random hexamers $(2.5 \mu \mathrm{M})$ and oligodT primers $(20 \mathrm{nM})$. The reverse transcription reaction was performed in a total volume of $25 \mu \mathrm{l}$ containing $0.2 \mathrm{mM}$ of each dNTP (Amersham Pharmacia BioTech, Piscataway, NJ), 200 U Moloney murine leukemia virus reverse transcriptase (M-MLV RT; Promega, Madison, $\mathrm{WI}$ ), and $25 \mathrm{U}$ RNAsin (Promega). Conditions for the reverse transcription reaction were $37^{\circ} \mathrm{C}$ for $30 \mathrm{~min}, 42^{\circ} \mathrm{C}$ for $15 \mathrm{~min}$, and $94^{\circ} \mathrm{C}$ for $5 \mathrm{~min}$. The cDNA was diluted to a final concentration of $8 \mathrm{ng} \mu \mathrm{l}^{-1}$ and stored at $-80^{\circ} \mathrm{C}$. Real-time quantitative PCR was performed using an AbiPrismR 7900 Sequence Detection System (PE Applied Biosystems, Foster City, CA) based on specific primers and general fluorescence detection with SYBR green. Cyclophillin was used to control for sample loading and to allow normalization between samples. The expression levels relative to cyclophillin were calculated following the equation: relative expression level $=2^{-\Delta \mathrm{Ct}}$, whereby $\Delta \mathrm{Ct}=\mathrm{Ct}_{\text {target }}-\mathrm{Ct}_{\text {cyclo }}$. Specific primers were designed across different constant region exons resulting in these primers:

GATA-3: Fw: 5' - ATGC C TGCGGACTCTAC- $3^{\prime}$, Rv: 5'-GGTGGTGGTGGTCTGAC-3';

T-BET: Fw: 5' - CAGGGAACCGCT TATATG-3', Rv: 5'-CTGGCTCTCCATCATTCA-3';

COX-2: Fw: 5' - A C C CGGACTGGAT TCTAT-3', Rv: 5'-GCTTCCCAGCTTTTGTAA-3';

FOXP 3: Fw: 5' - ACCTGGGATCAATGTGG-3', Rv: 5'-TGGCAGTGCTTGAGAAA-3';

C Y C L O : Fw: 5' - A A C C C C A C C G T G T T C T - 3', Rv: 5'-CATTATGGCGTGTAAAGTCA-3';

IFN - $\gamma:$ Fw: $5^{\prime}$ - CAAA AGGATGGTGACATGA-3' , Rv: 5'-GGGTTGTTGACCTCAAACT-3';

IL - 4: Fw: 5' - C A A G G T G C T T C G C A T A T T - 3' , Rv: 5'-GCATGGTGGCTCAGTACTA-3';

I L - 1 7: Fw: 5' - C T T G G C GCA A A A G T T G A - 3', Rv: 5'-TTGCTGGATGAGAACAGAA-3'.

\section{Statistics}

Statistically significant differences for ear-thickness measurements were determined using a one-way analysis of variance followed by a TurkeyKramer multiple comparisons test to assess differences between individual groups. $P<0.05$ was considered significant. All experiments were performed at least three times unless otherwise indicated.

SUPPLEMENTARY MATERIAL is linked to the online version of the paper at http://www.nature.com/mi

\section{ACKNOWLEDGMENTS}

We thank Ytje Simons-Oosterhuis, Rosalie Molenaar, Jan-Piet van Hamburg, Erwin van Gelderop, Dennis Bogaert, Bianca Jongmans, Mariëtte ter Borg, Debra Stuurman, and Ineke Maas for technical assistance and animal care. Richard Blumberg, Reina Mebius, Tom Cupedo, and André Boonstra are thanked for critical reading of this paper. This study was supported in part by the Netherlands Digestive Diseases Foundation.

\section{DISCLOSURE}

The authors declared no conflict of interest.

\section{() 2009 Society for Mucosal Immunology}

\section{REFERENCES}

1. Weiner, H.L. Induction and mechanism of action of transforming growth factor-beta-secreting Th3 regulatory cells. Immunol. Rev. 182, 207-214 (2001).

2. Thorstenson, K.M. \& Khoruts, A. Generation of anergic and potentially immunoregulatory CD25+CD4T cells in vivo after induction of peripheral tolerance with intravenous or oral antigen. J. Immunol. 167, 188-195 (2001).

3. Sakaguchi, S., Sakaguchi, N., Asano, M., Itoh, M. \& Toda, M. Immunologic self-tolerance maintained by activated T cells expressing IL-2 receptor alpha-chains (CD25). Breakdown of a single mechanism of self-tolerance causes various autoimmune diseases. J. Immunol. 155, 1151-1164 (1995).

4. Read, S. \& Powrie, F. CD4(+) regulatory T cells. Curr. Opin. Immunol. 13, 644-649 (2001).

5. Garside, P. \& Mowat, A.M. Oral tolerance. Semin. Immunol. 13, 177-185 (2001).

6. Wolvers, D.A. et al. Intranasally induced immunological tolerance is determined by characteristics of the draining lymph nodes: studies with OVA and human cartilage gp-39. J. Immunol. 162, 1994-1998 (1999).

7. Unger, W.W. et al. Nasal tolerance induces antigen-specific CD4+CD25regulatory $T$ cells that can transfer their regulatory capacity to naive CD4+ T cells. Int. Immunol. 15, 731-739 (2003).

8. Unger, W.W.J. et al. Early events in peripheral regulatory T cell induction via the nasal mucosa. J. Immunol. 171, 4592-4603 (2003).

9. Hauet-Broere, F. et al. Functional CD25 - and CD25+ mucosal regulatory $T$ cells are induced in gut draining lymphoid tissue within $48 \mathrm{~h}$ after oral antigen application. Eur. J. Immunol. 33, 2801-2810 (2003).

10. Chen, W. et al. Conversion of peripheral CD4+CD25 - naive T cells to CD4+CD25+ regulatory T cells by TGF-beta induction of transcription factor Foxp3. J. Exp. Med. 198, 1875-1886 (2003).

11. Coombes, J.L. et al. A functionally specialized population of mucosal CD103+ DCs induces Foxp3+ regulatory T cells via a TGF-\{beta\} and retinoic acid dependent mechanism. J. Exp. Med. 204, 1757-1764 (2007).

12. Sun, C.M. et al. Small intestine lamina propria dendritic cells promote de novo generation of Foxp3T reg cells via retinoic acid. J. Exp. Med. 204, 1775-1785 (2007)

13. Mucida, D. et al. Reciprocal Th-17 and regulatory $T$ cell differentiation mediated by retinoic acid. Science 317, 256-260 (2007).

14. Benson, M.J., Pino-Lagos, K., Rosemblatt, M. \& Noelle, R.J. All-trans retinoic acid mediates enhanced T reg cell growth, differentiation, and gut homing in the face of high levels of co-stimulation. J. Exp. Med. 204, 1765-1774 (2007).

15. Iwata, M. et al. Retinoic acid imprints gut-homing specificity on T cells. Immunity 21, 527-538 (2004). 
16. Annacker, O. et al. Essential role for CD103 in the T cell-mediated regulation of experimental colitis. J. Exp. Med. 202, 1051-1061 (2005).

17. Johansson-Lindbom, B. et al. Functional specialization of gut CD103+ dendritic cells in the regulation of tissue-selective T cell homing. J. Exp. Med. 202, 1063-1073 (2005).

18. Newberry, R.D., McDonough, J.S., Stenson, W.F. \& Lorenz, R.G. Spontaneous and continuous cyclooxygenase-2-dependent prostaglandin E2 production by stromal cells in the murine small intestine lamina propria: directing the tone of the intestinal immune response. J. Immunol. 166, 4465-4472 (2001).

19. Newberry, R.D., Stenson, W.F. \& Lorenz, R.G. Cyclooxygenase-2dependent arachidonic acid metabolites are essential modulators of the intestinal immune response to dietary antigen. Nat. Med. 5, 900-906 (1999)

20. Morteau, O. COX-2: promoting tolerance. Nat. Med. 5, 867-868 (1999).

21. Morteau, O. et al. Impaired mucosal defense to acute colonic injury in mice lacking cyclooxygenase-1 or cyclooxygenase-2. J. Clin. Invest. 105, 469-478 (2000)

22. Mowat, A.M. \& Widmer, M.B. A role for IL-4 in immunologically mediated enteropathy. Clin. Exp. Immunol. 99, 65-69 (1995).

23. Mizoguchi, A., Mizoguchi, E. \& Bhan, A.K. The critical role of interleukin 4 but not interferon gamma in the pathogenesis of colitis in T-cell receptor alpha mutant mice. Gastroenterology 116, 320-326 (1999).

24. Dohi, T. et al. Hapten-induced colitis is associated with colonic patch hypertrophy and Thelper cell 2-type responses. J. Exp. Med. 189, 1169-1180 (1999).

25. Iniguez, M.A., Punzon, C. \& Fresno, M. Induction of cyclooxygenase-2 on activated $\mathrm{T}$ lymphocytes: regulation of $\mathrm{T}$ cell activation by cyclooxygenase-2 inhibitors. J. Immunol. 163, 111-119 (1999).

26. Gilroy, D.W. et al. Inducible cyclooxygenase may have anti-inflammatory properties. Nat. Med. 5, 698-701 (1999)

27. Wolvers, D.A., van der Cammen, M.J. \& Kraal, G. Mucosal tolerance is associated with, but independent of, up-regulation Th2 responses. Immunology 92, 328-333 (1997).

28. Sharma, S. et al. Tumor cyclooxygenase-2/prostaglandin E2-dependent promotion of FOXP3 expression and CD4+ CD25+ T regulatory cell activities in lung cancer. Cancer Res. 65, 5211-5220 (2005).

29. Mucida, D. et al. Oral tolerance in the absence of naturally occurring Tregs. J. Clin. Invest. 115, 1923-1933 (2005).

30. Mantel, P.Y. et al. GATA3-driven Th2 responses inhibit TGF-beta1induced FOXP3 expression and the formation of regulatory T cells. PLOS Biol. 5, e329 (2007).

31. Wei, J. et al. Antagonistic nature of T helper $1 / 2$ developmental programs in opposing peripheral induction of Foxp3+ regulatory T cells. Proc. Natl. Acad. Sci. USA 104, 18169-18174 (2007).

32. Dardalhon, V. et al. IL-4 inhibits TGF-beta-induced Foxp3+ T cells and, together with TGF-beta, generates IL-9+ IL-10+ Foxp3(-) effector T cells Nat. Immunol. 9, 1347-1355 (2008).

33. Veldhoen, M. et al. Transforming growth factor-beta "reprograms" the differentiation of T helper 2 cells and promotes an interleukin 9-producing subset. Nat. Immunol. 9, 1341-1346 (2008)

34. Ni, J. et al. COX-2 inhibitors ameliorate experimental autoimmune encephalomyelitis through modulating IFN-gamma and IL-10 production by inhibiting T-bet expression. J. Neuroimmunol. 186, 94-103 (2007).
35. Lawrence, C.E. et al. IL-4-regulated enteropathy in an intestinal nematode infection. Eur. J. Immunol. 28, 2672-2684 (1998).

36. Garside, P. et al. Thelper 2 cells are subject to high dose oral tolerance and are not essential for its induction. J. Immunol. 154, 5649-5655 (1995).

37. Villarino, A.V. et al. Helper T cell IL-2 production is limited by negative feedback and STAT-dependent cytokine signals. J. Exp. Med. 204, 65-71 (2007).

38. Zheng, S.G., Wang, J., Wang, P., Gray, J.D. \& Horwitz, D.A. IL-2 is essential for TGF-beta to convert naive CD4+CD25- cells to CD25+Foxp3+ regulatory $T$ cells and for expansion of these cells. J. Immunol. 178, 2018-2027 (2007).

39. Baratelli, F. et al. Prostaglandin E2 induces FOXP3 gene expression and T regulatory cell function in human CD4+ T cells. J. Immunol. 175, 1483-1490 (2005)

40. Hammad, H. et al. Activation of the D prostanoid 1 receptor suppresses asthma by modulation of lung dendritic cell function and induction of regulatory T cells. J. Exp. Med. 204, 357-367 (2007)

41. Zhou, W. et al. Prostaglandin 12 analogs inhibit proinflammatory cytokine production and T cell stimulatory function of dendritic cells. J. Immunol. 178, 702-710 (2007)

42. Kabashima, K. et al. The prostaglandin receptor EP4 suppresses colitis, mucosal damage and CD4 cell activation in the gut. J. Clin. Invest. 109, 883-893 (2002).

43. Fukata, M. et al. Cox-2 is regulated by Toll-like receptor-4 (TLR4) signaling: Role in proliferation and apoptosis in the intestine. Gastroenterology 131, 862-877 (2006).

44. Nugent, P. \& Greene, R.M. Interactions between the transforming growth factor beta (TGF beta) and retinoic acid signal transduction pathways in murine embryonic palatal cells. Differentiation 58, 149-155 (1994).

45. Nugent, P., Potchinsky, M., Lafferty, C. \& Greene, R.M. TGF-beta modulates the expression of retinoic acid-induced RAR-beta in primary cultures of embryonic palate cells. Exp. Cell. Res. 220, 495-500 (1995)

46. Kaufmann, H.J. \& Taubin, H.L. Nonsteroidal anti-inflammatory drugs activate quiescent inflammatory bowel disease. Ann. Intern. Med. 107 513-516 (1987).

47. Bjarnason, I., Hayllar, J., MacPherson, A.J. \& Russell, A.S. Side effects of nonsteroidal anti-inflammatory drugs on the small and large intestine in humans. Gastroenterology 104, 1832-1847 (1993).

48. Felder, J.B. et al. Effects of nonsteroidal antiinflammatory drugs on inflammatory bowel disease: a case-control study. Am. J. Gastroenterol. 95, 1949-1954 (2000)

49. Henry, D. \& McGettigan, P. Selective COX-2 inhibitors: a promise unfulfilled? Gastroenterology 132, 790-794 (2007).

50. Libioulle, C. et al. Novel crohn disease locus identified by genome-wide association maps to a gene desert on 5 p13.1 and modulates expression of PTGER4. PLoS Genet. 3, e58 (2007).

51. Ling, K.W. et al. GATA3 controls the expression of CD5 and the T cell receptor during CD4T cell lineage development. Eur. J. Immunol. 37, 1043-1052 (2007)

52. Samsom, J.N. et al. Fc gamma RIIB regulates nasal and oral tolerance: a role for dendritic cells. J. Immunol. 174, 5279-5287 (2005). 